\title{
TREES OF MALAYA
}

Wayside Trees of Malaya

By E. J. H. Corner. Vol. I. Pp. vii +770. Vol. 2. Pp. ii +228 plates. (Singapore: Government Printing Office, 1940). 10 dollars.

T $\mathrm{T}$ is, we believe, unique to find monkeys co1 operating with a botanist in collecting flowering and fruiting specimens of trees for botanical investigation. This, however, has been done in Malaya by Mr. Corner, the author of the very interesting book under review, and his trained Berok monkeys, one of which is figured on the cover of the book, have provided him with much valuable material which otherwise might have been unattainable.

Some 950 species of Malayan "wayside" trees are described, and keys are provided for running them down to their families and genera. Anyone, therefore, who is interested in the trees, and is not a botanist, should be able to determine them without much difficulty, more especially as the distinguishing characters selected can be readily observed and are available throughout the year. The book is greatly enhanced by more than 250 excellent illustrations of different trees, which comprise the second volume.

The first volume consists mainly of descriptions of the various trees; accompanied often by useful text figures of flowers, fruits, and leaves, and keys to the genera and species, and much interesting information is given about the trees and their uses, and also about the vegetation of Malaya.

The book, in addition, includes a descriptive account of trees and how to name them. Forty pages are occupied by the elaborate keys, which are constructed on somewhat original lines. Mr. Corner has, in some cases, sacrificed clearness and accuracy for the sake of brevity in his constant use of the words "not so" as the alternative phrase in the couplet of distinguishing characters. In the first place it is not always easy to appreciate to what it applies, and in many cases it certainly does not apply to the whole of the statement with which it is contrasted.

Another unusual feature of the book is the arrangement of the families and the genera in alphabetical order. This may serve a useful purpose, but it is very disturbing to the botanist, since it brings into juxtaposition families wholly unrelated to one another. The Gymnosperms, however, are relegated to the end of the volume.

The book is provided with excellent indexes of English, Malay, and Latin names, and the inclusion of derivations of the generic and specific names is very welcome.

The volumes are a credit to the Government Printing Office, Singapore. The printing of the text and the reproduction of the fine photographs leave nothing to be desired.

A. W. Hill.

\section{AUSTRALIAN SHARKS AND RAYS}

The Fishes of Australia.

Part I : The Sharks, Rays, Devil-Fish and other Primitive Fishes of Australia and New Zealand. By Gilbert Percy Whitley. (Australian Zoological Handbook). Pp. 280. (Sydney: Royal Zoological Society of New South Wales, 1940.) 7s.6d.

$\mathrm{T}$ HIS useful handbook deals, not only with the Selachians (sharks, rays and chimaeras) of the seas of Australia and New Zealand, but also with creatures such as the lancelets, lampreys and hagfishes, and the unique lung-fish of Queensland. It is complete in itself, but is designed to form the first of a series of volumes on the fishes of Australia, which, when complete, should go far towards providing a long-standing desideratum. Within the compass of some 160 pages, the author has managed to include a brief description and figure of every known species of shark and ray, together with notes on its local range, maximum size attained, and so on. It is perhaps to be regretted that keys are not provided to assist identification of specimens; but the excellence of most of the illustrations, based almost entirely upon authentic local specimens, should serve to compensate for this omission. There can be little doubt that the intelligent reader making use of the systematic section of this book should have very little difficulty in determining most of the fishes likely to come to hand.

In addition to the systematic part, however, Mr. Whitley has managed to bring together a mass of valuable information concerning sharks and rays in general, which is presented in a comprehensive and interesting manner in the first sixty-seven pages of his book. This covers not only the breeding 